6. Strohl K, Bonnie R, Findley $L$, et al (1994). Sleep apnea, sleepiness and driving risk. American Journal of Respiratory and Critical Care Medicine. 150:1463-1473.

7. American Academy of Sleep Medicine (2014). International Classification of Sleep Disorders 3rd edition, American Academy of Sleep Medicine, United States of America.

8. Phạm Văn Lưu (2018). Nghiên cứu đặc điểm lâm sàng, cận lâm sàng và kết quả đo đả kí giấc ngủ của bệnh nhân ngừng thở khi ngủ, Luận văn Thạc sĩ Y học, Trường Đại học Y Hà Nội.

9. Singareddy $R$, Vgontzas AN, Fernandez MJ, et al (2012). Risk factors for incident chronic insomnia: a general population prospective study. Sleep Med. 13:346-353.

10. Vgontzas AN, Lin HM, Papaliaga $M$, et al (2008). Short sleep duration and obesity: the role of emotional stress and sleep disturbances. Int J Obes (Lond). 32(5):801-809.

\title{
XÂY DỰNG MÔ HÌNH PHÂN TÍCH CHI PHÍ - HIỆ QUẢ CỦA PEMBROLIZUMAB SO VỚI CÁC PHÁC ĐỒ CHUẨN TRONG ĐIỀU TRI UNG THƯ PHỔI KHÔNG TẾ BÀO NHỎ TẠI VIỆT NAM
}

\author{
Võ Thị Thu Hà ${ }^{1}$, Lê Đỗ Thành Đat ${ }^{2}$, \\ Nguyễn Cao Đức $\mathrm{Huy}^{2}$, Nguyễn Thị Thu Thủ ${ }^{2}$
}

\section{TÓM TẮT}

Phân tích chi phí - hiệu quả là môt công cu không thể thiếu khi ra quyết định đánh giá tính hợp lý của các can thiệp y tế, trong đó xây dựng mô hình được xem là một trong những bước quan trọng nhẩt. Pembrolizumab (PEM) được Cục Quản lý Thực phẩm và Dược phẩm Hoa Kỳ (Food and Drug Administration - FDA) công nhâan vào năm 2016 như thuốc đầu tay trong điều trị bệnh ung thư phổi không tế bào nhỏ (UTPKTBN). Tuy nhiên giá thành cao của thuốc là rào cản rất lớn khi chỉ đinh thuốc trên thực tế lâm sàng, đặc biệt ở các quốc gia đang phát triển như Việt Nam. Do đó cần phải xem xét tính khả thi của việc lựa chon thuốc trên lâm sàng dựa trên phân tích chi phí - hiệu quả. Với phương pháp mô hình hóa kết hợp với tổng quan tài liệu và tham vấn ý kiến các chuyên lâm sàng, nghiên cứu đã xây dựng đước mô hình phân tích chi phí - hiệu quả dựa trên phần mềm Microsoft Excel 2013 với cấu trúc mô hình gồm các trang tính toán cho các tham số đầu ra (chỉ số gia tăng chi phí - hiệu quả, độ nhạy). Mô hình cho phép phân tích chi phí hiệu quả của PEM so với hóa trị trong điều trị UTPKTBN giai đoạn tiến xa tại Việt Nam.

Tư khóa: Chi phí-hiệu quả, mô hình, pembrolizumab, ung thư phổi không tế bào nhỏ.

\section{SUMMARY \\ CONSTRUCT THE MODEL OF COST- EFFECTIVENESS ANALYSIS OF PEMBROLIZUMAB VERSUS STANDARD THERAPY IN THE TREATMENT OF NON- SMALL CELL LUNG CANCER IN VIETNAM}

\footnotetext{
${ }^{1}$ Trường Đại học Nguyễn Tất Thành

2Đại họ Y Dược TP Hồ Chí Minh

Chịu trách nhiệm chính: Nguyễn Thị Thu Thủy

Email: nguyenthuthuy@ump.edu.vn

Ngày nhận bài: 28.7.2021

Ngày phản biện khoa học: 27.9.2021

Ngày duyệt bài: 1.10.2021
}

Cost-effectiveness analysis is a tool used to aid decisions about which medical care should be offered, in which constructing model is considered one of the most important steps. Pembrolizumab (PEM) was recognized by the Food and Drug Administration (FDA) in 2016 as the first-line drug in the treatment of nonsmall cell lung cancer (NSCLC). However, the high price of drug has been creating a large barrier in using this drug in practice, especially in developing countries like Vietnam. It is necessary to consider the feasibility of drug selection in clinical practice based on cost effectiveness analysis. With modeling research method combined with literature review and indepth-interview with clinical experts, the cost - effectiveness analysis model has been built based on Microsoft Excel 2013 software with model structure including calculation pages for outcome parameters (Incremental cost effectiveness ratio (ICER), Sensitivity analysis). The model allows to evaluate the cost - effectiveness of PEM monotherapy versus chemotherapy in the treatment of NSCLC in Vietnam.

Keywords: Cost-effectiveness, model, pembrolizumab, non-small cell lung cancer.

\section{I. ĐĂT VẤN ĐỀ}

Nghiên cứu phân tích chi phí - hiệu quả là một trong những công cụ hỗ trợ trong quá trình ra quyết định giúp lựa chọn phương pháp điều trị tối ưu cho bệnh nhân. Trong đó xây dựng mồ hình phân tích chi phí - hiệu quả được xem là một trong những bước quan trọng đâu tiên của nghiên cứu. Pembrolizumab (PEM) (dưới tên biệt dược là KEYTRUDA ${ }^{\circledR}$ ) được Cục Quản lý Thực phẩm và Dược phẩm Hoa Kỳ (FDA) công nhận vào năm 2016 như liệu pháp đầu tay trong điểu trị bệnh ung thư phổi không tế bào nhỏ (UTPKTBN) di căn. Tuy nhiên giá thành cao của $\mathrm{PEM}$ là rào cản rất lớn khi chỉ định thuốc cho bệnh nhân, đặc biệt ở các quốc gia đang phát triển như Việt Nam. Do đó cân phải xem xét tính 
khả thi khi lựa chọn thuốc trong thực hành lâm sàng dựa trển phân tích chi phí - hiệu quả. Vì vậy nghiên cứu được tiến hành nhằm mục tiêu xầy dựng mô hình để phân tích chi phí - hiệu quả của PEM so với các phác đồ chuẩn trong điều trị UTPKTBN giai đoạn tiến xa phù hợp với bối cảnh điều trị tại Việt Nam.

\section{II. ĐỐI TƯỢG VÀ PHƯƠ'NG PHÁP NGHIÊN CỨU}

2.1 Đối tượng nghiên cứu: Mô hình phân tích chi phí - hiệu quả của PEM trong điều trị UTPKTBN giai đoạn tiến xa.

\subsection{Phương pháp nghiên cứu}

Phương pháp: Mô hình hóa kết hợp tổng quan tài liệu và tham vấn ý kiến chuyên gia.

Các bước xây dựng mô hình phân tích chi phí hiệu quả được trình bày trong hình 1 .

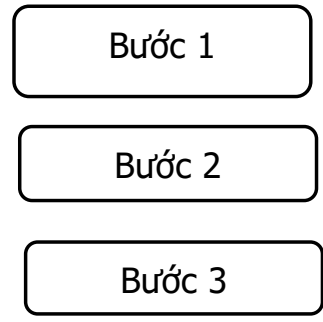

Bước 1: Xây dựng mô hình sơ bô được thực hiện dựa trên tổng quan các mô hình phân tích chi phí - hiệu quả của PEM so với các phác đồ chuẩn trong điều trị UTPKTBN giai đoạn tiến xa bằng phương pháp tổng quan hệ thống theo hướng dẫn PRISMA

Tìm kiếm các nghiên cứu: Nghiên cứu tiến hành tìm kiếm trên 4 nguồn cơ sở dữ liệu điện tử là Pubmed, Cochrane, Science Direct và Embase với các câu lệnh tìm kiếm dựa trên các từ khóa: "cost-effectiveness", "cost effectiveness" "pembrolizumab", "non-small cell lung carcinoma", "non-small cell lung cancer", "NSCLC".

Sàng lọc và lựa chọn nghiên cứu: Các nghiên cứu tìm thấy được lựa chọn thông qua các tiêu chí lựa chọn (nghiên cứu phân tích chi phí - hiệu quả của PEM với các phác đồ chuẩn trong điểu

Bảng 1. Đăc điểm của mô hình

\begin{tabular}{|c|c|c|}
\hline STT & Đặc điểm & Yêu câu \\
\hline 1 & Cấu trúc của mô hình & Mô tả các trạng thái bệnh lý theo diễn tiễn bệnh \\
\hline 2 & Chu kỳ mô hình & Khoảng thời gian tính toán chi phí, hiệu quả \\
\hline 3 & Khoảng thời gian & Thời gian ước lượng các thông số nghiên cứu \\
\hline 4 & Quần thể nghiên cứu & $\begin{array}{c}\text { Nhóm bệnh nhân đưa vào mô hình với các đặc điểm lâm } \\
\text { sàng nhất định được giả định trong nghiên cứu }\end{array}$ \\
\hline 5 & Các can thiệp so sánh & Các phác đồ được sử dụng trong nghiên cứu \\
\hline 6 & Tỉ lệ chiết khấu & $\begin{array}{c}\text { Tỷ lệ nhằm tính toán sự thay đổi giá trị của cả chi phí và } \\
\text { hiệu quả theo thời gian nghiên cứu }\end{array}$ \\
\hline 7 & Quan điểm nghiên cứu & Thể hiện khía cạnh, góc nhìn, phạm vi nghiên cứu \\
\hline 8 & Chức năng mô hình & Ước lượng chi phí - hiệu quả cưa từng phác đồ \\
\hline
\end{tabular}

Bước 2: Tham vấn ý kiến chuyên gia

Để mô hình hoàn thiện hơn và phản ánh đúng thực trạng điều trị UTPKTBN giai đoạn tiến xa tại Việt Nam, mô hình sẽ được hiệu chỉnh bởi các chuyên gia lâm sàng tại bệnh viện Chợ Rẫy và bênh viện Ung bướu TP Hồ Chí Minh. Các chuyên gia lâm sàng được lựa chọn thỏa mãn các tiêu chí lựa chọn (Bác sĩ cơ hữu, chuyên khoa ung thư, có kinh nghiệm điều trị trên 3 năm, đồng ý tham gia nghiên cứu) và tiêu chí 
loại trừ (Không cung cấp đầy đủ các thông tin cho buổi phỏng vấn).

Bước 3: Xây dựng mô hình hoàn thiện

Mô hình được xây dựng trên phần mềm Microsoft Excel 2013 với các trang tính toán, trang tham số đầu vào, đầu ra hoàn thiện để trở thành công cụ phân tích chi phí - hiệu quả của PEM trong điều trị UTPKTBN phù hợp với bối cảnh điều trị tại Việt Nam.

\section{KẾT QUẢ NGHIÊN CứU}

\subsection{Xây dựng mô hình phân tích chi phí}

- hiệu quả sở bộ. Dựa trên cơ sở dữ liệu và câu lệnh tìm kiếm, đề tài ghi nhận 251 nghiên cứu (23 nghiên cứu từ Pubmed, 16 nghiên cứu từ Cochrane, 58 nghiên cứu từ ScienceDirect và 154 bài từ Embase). Từ 251 nghiên cứu tìm được, đề tài loại bỏ 88 nghiên cứu trùng lặp, 140 nghiên cứu không thỏa tiêu chí lựa chọn, 11 nghiên cứu loại vì không có bài toàn văn. Cuối cùng, 12 nghiên cứu được đưa vào phân tích tổng quan hệ thống. Trích xuất dữ liệu về đặc điểm xây dựng mô hình của 12 nghiên cứu được trình bày trong bảng 2 .

\section{Bảng 2. Đặc điểm mô hình của 12 nghiên cứu được lựa chọn}

\begin{tabular}{|c|c|c|c|c|c|c|}
\hline STT & $\begin{array}{c}\text { Tác giả (năm xuất } \\
\text { bản) }\end{array}$ & Quan điểm & Mô hình & $\begin{array}{c}\text { Khoảng thời } \\
\text { gian }\end{array}$ & Chu kỳ & $\begin{array}{l}\text { Chiết } \\
\text { khấu }\end{array}$ \\
\hline 1 & $\begin{array}{c}\text { Huang và cs (2017) } \\
{[5]}\end{array}$ & Người chi trả & $\begin{array}{l}\text { Sống sót phân } \\
\text { vùng }\end{array}$ & 20 năm & 1 tuân & $3 \%$ \\
\hline 2 & $\begin{array}{l}\text { Georgieva và cs } \\
(2018)[3]\end{array}$ & $\begin{array}{l}\text { Hệ thống y tế (Anh), } \\
\text { người chi trả (Mỹ) }\end{array}$ & $\begin{array}{l}\text { Bayesian- } \\
\text { Markov }\end{array}$ & $\begin{array}{l}\text { Toàn thời } \\
\text { gian sống }\end{array}$ & 1 tháng & $3 \%$ \\
\hline 3 & $\begin{array}{c}\text { Insinga và cs (2018) } \\
{[6]}\end{array}$ & Người chi trả & \begin{tabular}{|c|}
$\begin{array}{c}\text { Sống sót phân } \\
\text { vùng }\end{array}$ \\
\end{tabular} & 20 năm & 1 tuần & $3 \%$ \\
\hline 4 & $\begin{array}{c}\begin{array}{c}\text { Bhadhuri và cS } \\
(2019)[2]\end{array} \\
\end{array}$ & Người chi trả & $\begin{array}{c}\text { Sống sót phân } \\
\text { vùng }\end{array}$ & 20 năm & 1 tuần & $3 \%$ \\
\hline 5 & $\begin{array}{c}\text { Huang và CS (2019) } \\
{[4]}\end{array}$ & Người chi trả & $\begin{array}{c}\text { Sống sót phân } \\
\text { vùng }\end{array}$ & 20 năm & 1 tuần & $3 \%$ \\
\hline 6 & $\begin{array}{c}\text { Insinga và cs (2019) } \\
{[7]}\end{array}$ & Người chi trả & $\begin{array}{c}\text { Sống sót phân } \\
\text { vùng }\end{array}$ & 20 năm & 1 tuần & $3 \%$ \\
\hline 7 & She và cs (2019) [8] & Người chi trả & Cây -Markov & 20 năm & 6 tuần & $3 \%$ \\
\hline 8 & \begin{tabular}{|c|} 
Zeng và cs (2019) \\
{$[11]$}
\end{tabular} & Người chi trả & Markov & 20 năm & 21 ngày & $3 \%$ \\
\hline 9 & $\begin{array}{c}\text { Zhou và cs (2019) } \\
{[12]}\end{array}$ & Người chi trả & Markov & 10 năm & $\begin{array}{l}\text { Không } \\
\text { đề cập }\end{array}$ & $3 \%$ \\
\hline 10 & $\begin{array}{c}\text { Wan và cs (2020) } \\
{[9]}\end{array}$ & Người chi trả & Markov & $\begin{array}{l}\text { Toàn thời } \\
\text { gian sống }\end{array}$ & 3 tuần & $3 \%$ \\
\hline 11 & Wu và cs (2020) [10] & Người chi trả & Cây -Markov & 20 năm & 21 ngày & $\begin{array}{c}3 \%- \\
5 \% \\
\end{array}$ \\
\hline 12 & \begin{tabular}{|c|}
$\begin{array}{c}\text { Barbier và cs (2021) } \\
{[1]}\end{array}$ \\
\end{tabular} & Người chi trả & Markov & 10 năm & 1 tháng & $3 \%$ \\
\hline \multicolumn{3}{|c|}{ 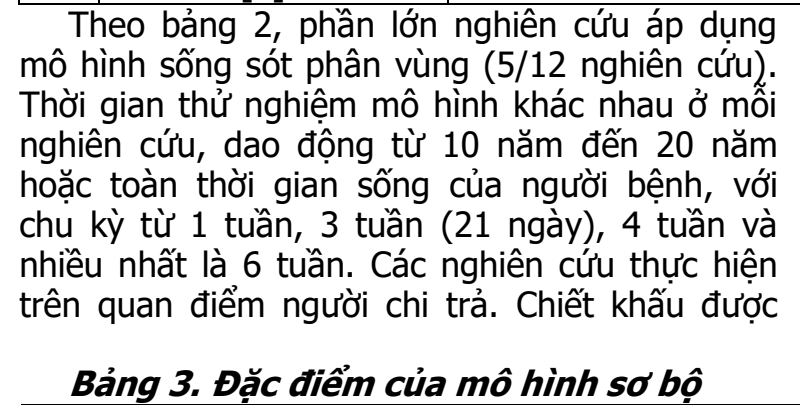 } & \multicolumn{4}{|c|}{$\begin{array}{l}\text { áp dụng cho cả chi phí và hiệu quả với giá trị 3\% } \\
\text { ở đa số nghiên cứu. } \\
\text { Dựa vào kết quả tổng quan hê thống, đề tà } \\
\text { xây dựng mô hình sống sót phẩn vùng với } \\
\text { trạng thái cơ bản: ổn định, tiến triển và tử vong } \\
\text { Mồ hình được xây dựng trong phần mêm } \\
\text { Microsoft Excel } 2013 \text { với cấu trúc gồm các trang } \\
\text { tính toán các thông số. Các đặc điểm của mố } \\
\text { hình sơ bộ được mô tả như trong bảng } 3 \text {. }\end{array}$} \\
\hline & ăc điếm của mô hình & \multicolumn{5}{|c|}{ Xây dựng mô hình sơ bộ } \\
\hline & Cấu trúc của mô hình & \multirow{2}{*}{\multicolumn{5}{|c|}{$\begin{array}{l}\text { Mô hình sống sót phân vùng với } 3 \text { trạng thái: ổn định } \\
1 \text { tuânn }\end{array}$}} \\
\hline & Chu kỳ mô hình & & & & & \\
\hline & oảng thời gian mô hình & \multicolumn{5}{|c|}{ Toàn thời gian sống của bệnh nhân } \\
\hline & Tỉ lệ chiết khấu & \multicolumn{5}{|c|}{$3 \%$} \\
\hline
\end{tabular}


VIETNAM MEDICAL JOURNAL N²2 - OCTOBER - 2021

\begin{tabular}{|c|c|}
\hline Quan điểm nghiên cứu & \begin{tabular}{|c|} 
Quan điểm bảo hiểm y tế (BHYT) \\
\end{tabular} \\
\hline Quần thể nghiên cứu & $\begin{array}{l}\text { Bệnh nhân có độ tuối } \geq 18 \text { tuối, được chẩn đoán UTPKTBN giai đoạn tiến } \\
\text { xa có PD-L1 } 50 \%\end{array}$ \\
\hline Can thiệp so sánh & PEM so với các phác đồ hóa trị liệu chuấn \\
\hline Giả định của mô hình & $\begin{array}{l}\text { Bệnh nhân có đặc điểm dịch tề tương đương với bệnh nhân trong nghiên } \\
\text { cứu lâm sàng }\end{array}$ \\
\hline Chức năng của mô hình & Cho phép phân tích chi phí-hiêu quả của PEM so với các phác đồ chuẩn \\
\hline
\end{tabular}

3.2 Tham vấn ý kiến chuyên gia

Dựa trên tham vấn ý kiến nhóm chuyên gia, đề tài ghi nhận những hiệu chỉnh cần được thực hiện với kết quả trình bày trong bảng 4.

Bảng 4. Tổng hợp tham vấn ý kiến chuyên gia về mô hình sơ bộ

\begin{tabular}{|c|c|}
\hline Đặc điểm mô hình & Ý kiến đóng góp của các chuyên gia \\
\hline $\begin{array}{l}\text { Cấu trúc mô hình phân vùng } \\
\text { sống sót }\end{array}$ & Phợp với diễn tiến bệnh UTPKTBN giai đoạn tiến xa \\
\hline Chu kỳ mô hình & Hiệu chỉnh 3 tuần phù hợp với lịch trình tái khám của bệnh nhân \\
\hline Khoảng thời gian & Phù hợp \\
\hline Tỉ lệ chiết khấu & Phù hợp \\
\hline Quan điểm nghiên cứu & Phù hợp \\
\hline Quân thể nghiên cứu & Phù hợp \\
\hline Can thiệp so sánh & Phù hợp \\
\hline Giả đinh mô hình & Bố sung thêm môt số giả đinh liên quan đến điều tri \\
\hline Chức năng mô hình & $\begin{array}{l}\text { Bố sung thêm chức năng cho phép đánh giá các yếu tố ảnh } \\
\text { hưởng đến chi phí - hiệu quả của mô hình }\end{array}$ \\
\hline
\end{tabular}

3.3 Mô hình đánh giá chi phí - hiêu quả hoàn thiện. Sau khi tham vấn ý kiến chuyên gia lâm sàng, mô hình được hoàn thiện với cấu trúc bao gồm các trang tính toán được xây dựng bằng phần mềm Microsoft Excel 2013 được trình bày như trong hình 2.

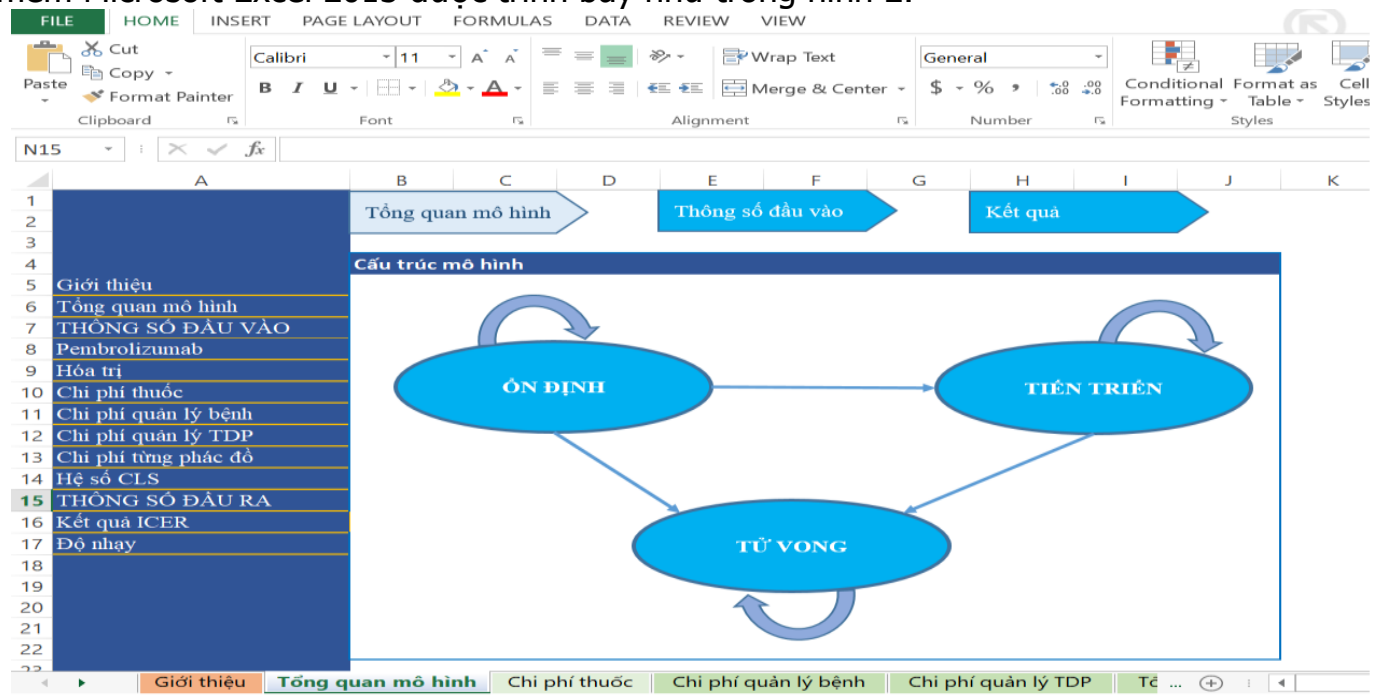

Hình 2. Mô hình phân tích chi phí - hiệu quả xây dựng trên phân mèm Excel

Giả định của mô hình

- Bệnh nhân có đặc điểm dịch tễ, tỉ lệ biến chứng và tác dụng phụ trong điêu trị tương đương với tỉ lệ được nghiên cứu của nghiên cứu lâm sàng Keynote 024.

- Giá thuốc và dịch vụ y tế ở các bệnh viện tuân thủ bảng giá của Bộ Y tế.

- Bệnh nhân tuân thủ đúng phác đồ hướng dẫn chẩn đoán và điều trị.
Chức năng của mô hình

- Ước lượng tỉ lệ bệnh nhân ở mỗi trạng thái tại các thời điểm.

- Phân tích chi phí - hiệu quả của PEM so với các phác đồ chuẩn.

- Cho phép đánh giá các yếu tố ảnh hưởng đến chi phí - hiệu quả.

Thông số đầu vào và đầu ra của mô hình được trình bày trong bảng 5 . 
Bảng 5. Các thông số đầu vào và đầu ra của mô hình

\begin{tabular}{|c|c|c|}
\hline Các thông số & Nội dung & Tên gọi trang tính toán \\
\hline \multicolumn{3}{|c|}{ Thông số đâu vào } \\
\hline $\begin{array}{c}\text { Số lượng bệnh nhân } \\
\text { ở từng trạng thái } \\
\text { theo thời gian }\end{array}$ & $\begin{array}{c}\text { Ước lượng bệnh nhân ở các trạng thái: ổn định, } \\
\text { tiển triển, tử vong theo thời gian }\end{array}$ & $\begin{array}{l}\text { Pembrolizumab } \\
\text { Hóa trị }\end{array}$ \\
\hline Chi phí & $\begin{array}{l}\text { Chi phí thuốc, chi phí quản lý bệnh }{ }_{c} \text { chi phí điều } \\
\text { trị tác dụng phụ, tổng chi phí mối phác đồ }\end{array}$ & $\begin{array}{l}\text { CP thuốc, CP quản lý bênh, } C P \\
\text { quản lý TDP, CP từng phác đồ }\end{array}$ \\
\hline $\begin{array}{l}\text { Hệ số chất lượng } \\
\text { sống }\end{array}$ & $\begin{array}{c}\text { Hệ số chất lượng sống theo thời gian đến khi } \\
\text { bệnh nhân tử vong }\end{array}$ & Hệ số CLS \\
\hline \multicolumn{3}{|c|}{ Thông số đâu ra } \\
\hline $\begin{array}{l}\text { Chỉ số gia tăng chi } \\
\text { phí - hiệu quả }\end{array}$ & $\begin{array}{c}\text { Chỉ số gia tăng chi phí - hiệu quả của phác đồ } \\
\text { điều trị }\end{array}$ & Kết quả \\
\hline Phân tích độ nhạy & Độ nhạy 1 chiêu và xác suất & Phân tích độ nhạy \\
\hline
\end{tabular}

\section{BÀN LUẬN}

Đề tài đã xây dựng hoàn thiện mô hình phân tích chi phí - hiệu quả của PEM so với các phác đồ chuẩn trong điều trị UTPKTBN giai đoạn tiến xa trên nền tảng Microsoft Excel 2003. Đây được coi là công cụ quan trọng để đánh giá tính chi phí - hiệu quả của PEM cũng như ước lượng mức độ ảnh hưởng của các thông số đầu vào lên kết quả và tính chắc chắn của các kết quả thu được. Mặc dù trên thế giới có nhiều nghiên cứu phân tích chi phí - hiệu quả của PEM đã được tiến hành với phương pháp mô hình hóa nhưng tại Việt Nam chưa có đề tài nào tương tự được thực hiện cho đến thời điểm hiện tại. Hơn nữa để có thể ứng dụng mô hình tại Việt Nam, cần có những điều chỉnh phù hợp với thực tế lâm sàng. Vì vậy, là nghiên cứu đầu tiên được thực hiện liên quan đển chủ đề này, đề tài mang tính ứng dụng cho những nghiên cứu về chi phí - hiệu quả của PEM trong tương lai đồng thời có giá trị tham khảo cho những đề tài tương tự. Đề tài đã lựa chọn mô hình sống sót phân vùng để xây dựng với 3 trạng thái cơ bản: ổn định, tiến triển và̀ tử vong tương tự với các mô hình trong phần lớn nghiên cứu đã được xây dựng trên thế giới như nghiên cứu của Insinga (2019), Huang (2019),...[4], [7]. Khác với mô hình Markov thường được sử dụng trong các nghiên cứu về chi phí - hiệu quả tại Việt Nam trước đây, mô hình sống sót phân vùng phù hợp hơn với các bệnh ung thư như UTPKTBN giai đoạn tiến xa khi mà bệnh nhân đang ở trạng thái bệnh tiến triển sau không thể quay trở lại trạng thái bệnh ban đầu. Mô hình sống sót phẩn vùng có thể sử dụng trực tiếp thông số đầu vào là các đường cong sống sót Kaplan- Meier được công bố trong các thử nghiệm lâm sàng và từ đó có thể thiết lập được các hàm sống sót để ước tính tỉ lệ bệnh nhẩn ở mỗi trạng thái mà không cần xác định tần số chuyển đổi giữa các trang thái như mô hình Markov. Mô hình được điều chỉnh bởi các chuyên gia lâm sàng để phù hợp với bối cảnh điều trị tại Việt Nam. Trong các nghiên cứu nước ngoài, khung thời gian trong mô hình sống sót phân vùng thường là 10 hoặc 20 năm, đề tài lựa chọn khung thời gian là toàn thời gian sống của bệnh nhân để phù hợp với thực trạng của bệnh UTPKTBN giai đoạn tiến xa từ đó đánh giá được sự khác biệt về chi phí - hiệu quả giữa các phác đồ điều trị. Sử dụng hợp lý các phương pháp phân tích kinh tế dược, mô hình xây dựng có thể cung cấp công cụ hữu ích cho cơ quan quản lý y tế, các chuyên gia lâm sàng trong việc lựa chọn phác đồ điều trị tối ưu cho bệnh nhẩn và từ đó đề xuất các chính sách y tế để làm giảm gánh nặng kinh tế cho bệnh nhân và xã hội.

\section{KẾT LUÂN}

Mô hình được xây dựng trong phần mềm Microsoft Excel 2013 với cấu trúc mô hình bao gồm các trang tính toán các tham số đầu ra cho phép phân tích chi phí - hiệu quả của PEM trong điều trị UTPKTBN, đánh giá được các yếu tố liên quan đến chi phí - hiệu quả và cho phép cập nhật các tham số đầu vào để thu được kết quả cập nhật nhất cho từng thời điểm nghiên cứu nhất định.

\section{TÀI LIẸU THAM KHẢO}

1. Barbier M. C. et al (2021), "A cost-effectiveness analysis of pembrolizumab with or without chemotherapy for the treatment of patients with metastatic, non-squamous non-small cell lung cancer and high PD-L1 expression in Switzerland", Eur J Health Econ, 22(5), pp. 669-677.

2. Bhadhuri A. et al (2019), "Cost effectiveness of pembrolizumab vs chemotherapy as first-line treatment for metastatic NSCLC that expresses high levels of PD-L1 in Switzerland", Swiss Med Wkly, 149, pp. w20170.

3. Georgieva M. et al (2018),"Cost-effectiveness 
of pembrolizumab as first-line therapy for advanced non-small cell lung cancer", Lung Cancer, 124, pp. 248-254.

4. Huang $M$ et al (2019), "Cost-effectiveness of pembrolizumab versus chemotherapy as first-line treatment in PD-L1-positive advanced non-smallcell lung cancer in the USA", Immunotherapy, 11(17), pp. 1463-1479.

5. Huang M. et al (2017), "Cost Effectiveness of Pembrolizumab vs. Standard-of-Care Chemotherapy as First-Line Treatment for Metastatic NSCLC that Expresses High Levels of PD-L1 in the United States", Pharmacoeconomics, 35(8), pp. 831-844.

6. Insinga $\mathbf{R}$. P. et al (2018), "Cost-effectiveness of pembrolizumab in combination with chemotherapy in the 1st line treatment of nonsquamous NSCLC in the US", J Med Econ, 21(12), pp. 1191-1205.

7. Insinga R. P. et al (2019), "Cost-effectiveness of pembrolizumab in combination with chemotherapy versus chemotherapy and pembrolizumab monotherapy in the first-line treatment of squamous non-small-cell lung cancer in the US", Curr Med Res Opin, 35(7), pp. 1241-1256.
8. She L. et al (2019), "Cost-effectiveness analysis of pembrolizumab versus chemotherapy as firstline treatment in locally advanced or metastatic non-small cell lung cancer with PD-L1 tumor proportion score $1 \%$ or greater", Lung Cancer. 138 , pp. 88-94.

9. Wan N. et al (2020), "Cost-effectiveness analysis of pembrolizumab plus chemotherapy with PD-L1 test for the first-line treatment of NSCLC, Cancer Med, 9(5), pp. 1683-1693.

10.Wu B. et al (2020), "The effect of PD-L1 categories-directed pembrolizumab plus chemotherapy for newly diagnosed metastatic nonsmall-cell lung cancer: a cost-effectiveness analysis", Transl Lung Cancer Res, 9(5), pp. 1770-1784.

11.Zeng $X$. et al (2017), "Cost-effectiveness analysis of pembrolizumab plus chemotherapy for previously untreated metastatic nonsmall cell lung cancer in the USA", TheOncologist, 22, pp. 1392-1399.

12.Zhou K. et al (2019), "Cost-effectiveness analysis of pembrolizumab monotherapy and chemotherapy in the non-small-cell lung cancer with different PD-L1 tumor proportion scores", Lung Cancer, 136, pp. 98-101.

\title{
ĐÁNH GIÁ HIỆU QUẢ CỦA PHƯƠNG PHÁP CAN THIỆP NộI MẠCH TRONG ĐIỀU TRI CHẢY MÁU TÁ TRÀNG
}

\author{
Lê Thanh Dũng ${ }^{1}$, Trương Bích $A^{2}{ }^{2}$, Thân Văn $S^{1}$
}

\section{TÓM TẮT}

Mục tiêu: Đánh giá tính hiệu quả và an toàn của phương pháp can thiệp nút mạch cầm máu trong điều trị bênh nhân (BN) chảy máu tá tràng cấp tính. Đối tượng và phương pháp nghiên cứu: Nghiên cứu hồi cứu/tiến cứu mô tả từ 01/01/2020 đến 31/05/2021, 21 BN được chẩn đoán chảy máu tá tràng và can thiệp nội mạch cầm máu tại Bệnh viên Hữu nghị Việt Đức. Kết quả: Tỷ lệ thành công về kỹ thuật và lầm sàng lần lượt là $21 / 21(100 \%)$ và $14 / 21(66,7 \%)$ trường hợp. Tỷ lệ biến chứng sớm chảy máu tái phát chiếm 4/21(19\%), trong đó 1 BN được nút mach lần hai, 3 BN được nội soi nhắc lại hoặc phẫu thuật câm máu sau nút, 1 BN u tá tràng sau nút mach có biến chứng thiếu máu tá tràng được kiểm tra lại bằng nội soi và điều trị phẫu thuật. Tỷ lệ tử vong trong vòng 30 ngày sau nút là $9 / 21(42.8 \%)$, trong đó 2 BN nặng lên do u tiến triển mà không có biểu hiênn chảy máu tiêu hóa tái phát. Kết luận: Can thiệp nút mach cầm máu là một phương pháp an toàn, hiêuu quả trong kiểm soát chảy máu tá tràng thất bại với điêuu trị cầm máu

\footnotetext{
${ }^{1}$ Bệnh viện Hữu nghị Việt Đức

${ }^{2}$ Bệnh viện Đa khoa Hồng Ngọc

Chịu trách nhiệm chính: Lê Thanh Dũng

Email: Drdung74@gmail.com

Ngày nhân bài: 28.7.2021

Ngày phản biên khoa họ: 28.9.2021

Ngày duyệt bài: 4.10.2021
}

qua nội soi, nhất là đối với những BN thuộc nhóm cao tuổi, có bệnh lý nội khoa kết hợp.

\section{SUMMARY \\ THE RESULTS OF THE ENDOVASCULAR EMBOLIZAITON IN TREATMENT OF DUODENAL BLEEDING}

Purpose: To evaluate the efficacy and safety of endovascular embolization in treatment of acute duodenal bleeding. Materials and method: Retrospective and prospective descriptive study, from January 2020 to June 2021, 21 cases diagnosed as duodenal bleeding, were alternatively attempted to the transcatheter arterial embolization (TAE) under the guidance of DSA (digital subtraction angiography). Results: The technical and clinical success rates of TAE were respectively $21 / 21(100 \%)$ and $14 / 21$ $(66,7 \%)$. The early complication of recurrent bleeding rate for $4 / 21(19 \%)$, of which 1 patient was embolized for the second time, the last 3 cases were repeated endoscopic or hemostasis surgery secondary. There was 1 case with duodenal ischemic complication checked by repeated endoscopic post embolotherapy due to duodenal tumor, followed by surgical intervention. Mortality rate within 30 days after embolization was $9 / 21(42.8 \%), 2$ patients had poor prognosis due to tumor progression without rebleeding, the remaining patients was affected by underlying diseases, coagulation disorders, death leaded by hemorrhagic shock or multiple organ failure. 